\title{
Assessment of Knowledge and Consumption Patterns of Soybean, Moringa Oleifera, Aloe Vera and Other Agro-Resources: The Case of the Elderly and Pregnant/Nursing Women in Lome, Togo
}

\author{
Tonyi R. Mensah, Msc \\ Mamy Eklou-Lawson, PhD
}

Laboratoire de Microbiologie et de Contrôle Qualité des Denrées Alimentaires, Ecole Supérieure des Techniques Biologiques et Alimentaires, Université de Lomé, Lomé, Togo

Fifonsi A. Gbeasor-Komlanvi, MD, MPH

Didier Koumavi Ekouevi, Professor, $\mathrm{MD}, \mathrm{PhD}$

Département de Santé Publique, Faculté des Sciences de la Santé, Université de Lomé, Lomé, Togo

Damintoti S. Karou, Associate Professor, PhD

Yaovi Ameyapoh, Professor, PhD

Comlan A. de Souza, Professor, PhD

Laboratoire de Microbiologie et de Contrôle Qualité des Denrées Alimentaires, Ecole Supérieure des Techniques Biologiques et Alimentaires, Université de Lomé, Lomé, Togo

Doi: 10.19044/esj.2018.v14n3p179 URL:http://dx.doi.org/10.19044/esj.2018.v14n3p179

Abstract

Purpose: To assess how soybean products and other agro-resources are known and consumed by some vulnerable populations in Lome (Togo). Methods: A cross sectional study was conducted from March to April 2015 among people aged 50 years and over attending two Pension Fund departments and pregnant and nursing women attending Bè Hospital in Lome. Data were collected using a pre-tested face-to-face questionnaire. Participants were surveyed about their knowledge and consumption habits of soybean, Moringa oleifera, Aloe vera products and other agro-resources. Results: A total of 847 respondents were included in the study with 426 pregnant/nursing women and 421 people aged 50 years and over. The majority of respondents were married $(39.5 \%)$ and $45.3 \%$ of the elderly people were widowed. At least nine over ten respondents $(96 \%)$ knew soybean products and $76.8 \%$ of them reported a lifetime consumption of soybean products. The available and most consumed agro-resources included tofu $(82.7 \%)$, moringa leaves $(87.2 \%)$ and soy flour 
(29.7\%). The least consumed products were soymilk, soy yogurt and moringa juice. Respondents also reported using moringa tea and soap, as well as Aloe vera juice and toothpaste. Conclusion: Soybean products and other agricultural resources are well known and consumed by people living in Lome. Data on actual food intake is useful to public health professionals and food safety risk assessors. It is important to inform the public at large of the recognized benefits of some foods that will provide solutions to their health problems.

Keywords: Soybean products, agro-resources, consumption, vulnerable populations, Togo

\section{Introduction}

As a result of changes in diets and lifestyles, chronic diseases are increasingly affecting both developed and developing countries (Cappuccio \& Miller, 2016). Infectious communicable diseases such as HIV/AIDS, tuberculosis, cholera, and diarrhoea challenges health systems have been facing in Africa. However, in the last three decades, there has been rapid increase in the prevalence of chronic non-communicable diseases (NCDs) such as cardiovascular diseases, cancer, osteoporosis, diabetes, obesity and hypercholesterolemia (Chiwanga et al., 2016; Dalal et al., 2011; Guwatudde et al., 2015). Consequently, sub-saharan African countries including Togo carry a crushing double burden of diseases.

Togolese people are increasingly concerned about their health status in general. Because their attention is particularly related to the early occurrence of these chronic diseases in younger patients as described by several authors (Adeniyi, Laurence, Volmink, \& Davids, 2017; Darre et al., 2015; Hussein et al., 2017; Pio et al., 2014) . They become very active in finding preventive solutions through what can be called a "reverse nutritional transition" based on a health-promoting whole food (Hever \& Cronise, 2017). In the case of illness, and for several reasons, they even believe that food-oriented approaches can totally replace medical treatment. Overall, it clearly appears that people return to very frequent consumption of some nutritional agroresources. Thus, soy, Moringa oleifera, spirulina and Aloe vera derived foods abound in both specialty food shops and pharmacies in Lome. These products convey very attractive messages like health claims, even if the evidence is not formally established. In addition, some people go so far as to excessively and regularly consume products such as whole cloves of garlic for their antihypertensive properties or some algae extracts that are supposed to be the key to longevity. Although these products actually contain vital nutrients needed to promote a good development of the human body or improve some 
physiological functions, there are concerns that, just like medicines, they could be harmful in case of abuse.

The literature lacks data either about practices or consumption of such products in Togo. Reliable data are needed and will certainly be useful for the implementation of regulatory policies in this emerging field of "functional foods" in our country. The purpose of this study is to assess knowledge and consumption patterns of soybean, Moringa oleifera and other products in two vulnerable groups of populations in Lome. This stands as a first step in a general description approach for Togolese people's food consumption habits.

\section{Methods}

\section{Study setting and design}

This is a descriptive cross-sectional study conducted among the elderly and pregnant and nursing women living in Lome from March to April 2015. People aged 50 years and over were eligible for the study and were recruited from the two Pension Fund departments located in Klikame and Tokoin Doumassesse (districts of Lome). Pregnant and nursing women were recruited from Hôpital du District $\mathrm{N}^{\circ} 3$ (Bè Hospital) which is a reference hospital for maternity and infant care in Lome with regards to high quality service and attendance rate.

\section{Study sampling}

Having no prior data available for sample size calculation, we assumed soy food products consumption in Togo to be $50 \%$. Therefore, with parameters set at $5 \%$ for the precision and $5 \%$ for the significance level, at least 384 participants should be included the study for each population under study. Participants were selected using convenience sampling: all people aged 50 years and over attending selected Pension Fund departments and pregnant and nursing women who were hospitalized or attending prenatal care at selected hospital were approached to participate in the research study.

\section{Data Collection}

Data was collected using a well-structured questionnaire through faceto-face interviews. After informed consent was received, the questionnaire was administered to selected participants. The questionnaire included items on socio-demographic characteristics (gender, age, education level and occupation), knowledge and consumption of soy food products, knowledge and consumption of moringa and other agro-resources products. The main question included the following: Do you know soy / moringa and other products? For which reasons do you think it is interesting to eat soy / moringa and other products? Have you ever eaten soy-derived products? Which ones and how often? 
Before the main data collection, the tools were pre-tested by interviewers who attended a one-day training session.

\section{Data processing and analysis}

Data were entered into an Epidata database and imported into STATA version 9.0 for analysis. Data entered into Epidata were stored at least once a day on two external hard drives. Data entry and cleaning were performed by trained staff. Proportions were presented as descriptive statistics for all qualitative variables with their $95 \%$ confidence interval.

\section{Results}

The study included a total of 847 respondents with 426 pregnant/nursing women and 421 people aged 50 years and over.

\section{Socio-demographic characteristics of respondents}

Respondent's socio-demographic data are presented in table 1 below. With respect to gender among the elderly, $19.4 \%$ of respondents were males while $80.6 \%$ were females. The majority of respondents were married $(39.5 \%)$ and $45.3 \%$ of the elderly people were widowed. Furthermore, the distribution of respondents based on their educational level showed that $18.4 \%$ have attended primary school, $11 \%$ have not completed secondary school, $3.1 \%$ have completed secondary school, and $64 \%$ were not willing to disclose their level of education. Only $3.5 \%$ of surveyed participants have attained higher education.

Table 1: Socio-demographic characteristics of respondents

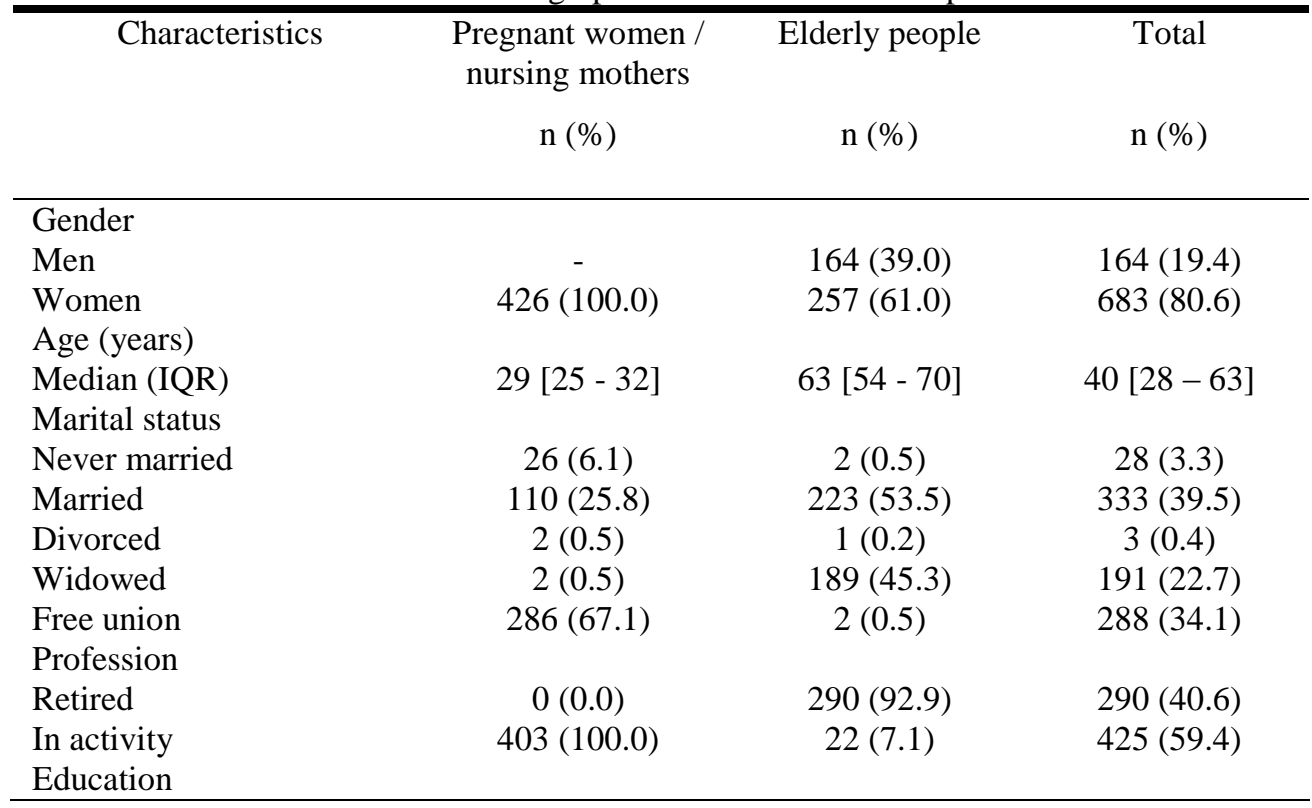




\begin{tabular}{lccc}
\hline Primary school & $138(32.4)$ & $13(3.3)$ & $151(18.4)$ \\
$\begin{array}{l}\text { Did not complete } \\
\text { secondary school }\end{array}$ & $78(18.3)$ & $12(3.1)$ & $90(11.0)$ \\
$\begin{array}{l}\text { Completed secondary } \\
\text { education }\end{array}$ & $21(5.0)$ & $4(1.0)$ & $25(3.1)$ \\
Higher education & $27(6.3)$ & $2(0.5)$ & $29(3.5)$ \\
Not willing to answer & $162(38.0)$ & $362(92.1)$ & $524(64.0)$ \\
\hline
\end{tabular}

IQR: interquartile range

\section{Knowledge and consumption habits of soy products}

The majority of surveyed people $(96 \%)$ knew soybean products and $76.8 \%$ [95\% confidence interval $(95 \% \mathrm{CI}): 73.8-79.6]$ of them reported a lifetime consumption of soybean products (table 2). Tofu (82.7\%), soybean flour $(29.7 \%)$ and soymilk $(12.5 \%)$ were the mostly consumed soybean products by respondents. $7.1 \%$ of soybean products consumers reported using other products such as soy shampoo and soy soap.

Table 2: Respondents knowledge and consumption habits of soybean products

\begin{tabular}{|c|c|c|c|}
\hline & Pregnant women and nursing mothers & Elderly people & Total \\
\hline & n (\%) & n (\%) & n (\%) \\
\hline \multicolumn{4}{|c|}{ Knowledge of soybean products } \\
\hline No & $13(3.1)$ & $21(5.0)$ & $34(4.0)$ \\
\hline Yes & $413(96.9)$ & $397(95.0)$ & $810(96.0)$ \\
\hline \multicolumn{4}{|c|}{ Have you ever consumed soybean products? } \\
\hline No & $87(20.5)$ & $108(25.9)$ & $195(23.2)$ \\
\hline Yes & $338(79.5)$ & $309(74.1)$ & $647(76.8)$ \\
\hline \multicolumn{4}{|c|}{ Consumption of soymilk } \\
\hline No & $297(87.6)$ & $271(87.4)$ & $568(87.5)$ \\
\hline Yes & $42(12.4)$ & $39(12.6)$ & $81(12.5)$ \\
\hline \multicolumn{4}{|c|}{ Consumption of soy yogurt } \\
\hline No & $335(98.8)$ & $308(99.4)$ & $643(99.1)$ \\
\hline Yes & $4(1.2)$ & $2(0.6)$ & $6(0.9)$ \\
\hline \multicolumn{4}{|c|}{ Consumption of tofu } \\
\hline No & $79(23.3)$ & $33(10.6)$ & $112(17.3)$ \\
\hline Yes & $260(76.7)$ & $277(89.4)$ & $537(82.7)$ \\
\hline \multicolumn{4}{|c|}{ Consumption of soybean flour } \\
\hline No & $207(61.1)$ & $249(80.3)$ & $456(70.3)$ \\
\hline Yes & $132(38.9)$ & $61(19.7)$ & $193(29.7)$ \\
\hline \multicolumn{4}{|c|}{ Consumption of soybread } \\
\hline No & $321(94.7)$ & $289(93.2)$ & $610(94.0)$ \\
\hline Yes & $18(5.3)$ & $21(6.8)$ & $39(6.0)$ \\
\hline \multicolumn{4}{|c|}{ Consumption of soybean oil } \\
\hline No & $328(96.8)$ & $301(97.1)$ & $629(96.9)$ \\
\hline Yes & $11(3.2)$ & $9(2.9)$ & $20(3.1)$ \\
\hline \multicolumn{4}{|c|}{ Consumption of other soybean products } \\
\hline No & $300(88.5)$ & $303(97.7)$ & $603(92.9)$ \\
\hline Yes & $39(11.5)$ & $7(2.3)$ & $46(7.1)$ \\
\hline
\end{tabular}


Consumption of soy products among children under 6 months of age

Some pregnant women and nursing mothers reported feeding soybean products children under 6 months of age. $12.1 \%, 0.4 \%$ and $0.8 \%$ of women were giving their children soybean flour in the form of porridge, soymilk and other soy products (tofu or juice) respectively. None of the respondents reported feeding soy yogurt their children.

\section{Knowledge and consumption habits of Moringa oleifera and other agro- resources}

At least nine participants over ten (96.6\%) knew Moringa oleifera products and $71.2 \%$ of them declared consuming these products. As reported in table 3, moringa leaves were consumed by $87.2 \%$ of respondents in the form of legume and infusion; moringa leaf powder were consumed by $12.5 \%$ of them and other moringa products such as soap, cream or toothpaste were consumed by $24.6 \%$ (95\%CI: $25.7-31.9$ ). Only $3.2 \%$ of respondents reported moringa drink consumption.

In addition, respondents reported knowledge and consumption of other agro-resources such as baobab fruit, Aloe vera, pineapple, orange and spinach (table 4).

Table 3. Respondents knowledge and consumption habits of $M$. oleifera products

\begin{tabular}{|c|c|c|c|}
\hline & $\begin{array}{l}\text { Pregnant women/nursing mothers } \\
\text { n }(\%)\end{array}$ & $\begin{array}{l}\text { Elderly people } \\
\text { n }(\%)\end{array}$ & $\begin{array}{l}\text { Total } \\
\text { n }(\%)\end{array}$ \\
\hline \multicolumn{4}{|c|}{ Knowledge of $M$. oleifera } \\
\hline No & $16(3.8)$ & $13(3.1)$ & $29(3.4)$ \\
\hline Yes & $410(96.2)$ & $406(96.9)$ & $816(96.6)$ \\
\hline \multicolumn{4}{|c|}{ Have you ever consumed $M$. oleifera products? } \\
\hline No & $163(38.3)$ & $80(19.1)$ & $243(28.8)$ \\
\hline Yes & $263(61.7)$ & $339(80.9)$ & $602(71.2)$ \\
\hline \multicolumn{4}{|c|}{ Consumption of $M$. oleifera leaves } \\
\hline No & $33(12.5)$ & $44(13.0)$ & $77(12.8)$ \\
\hline Yes & $230(87.5)$ & $295(87.0)$ & $525(87.2)$ \\
\hline \multicolumn{4}{|c|}{ Consumption of $M$. oleifera drink } \\
\hline No & $258(98.1)$ & $325(95.9)$ & $583(96.8)$ \\
\hline Yes & $5(1.9)$ & $14(4.1)$ & $19(3.2)$ \\
\hline \multicolumn{4}{|c|}{ Consumption of $M$. oleifera leaves flour } \\
\hline No & $236(89.7)$ & $291(85.8)$ & $527(87.5)$ \\
\hline Yes & $27(10.3)$ & $48(14.2)$ & $75(12.5)$ \\
\hline \multicolumn{4}{|c|}{ Consumption of other $M$. oleifera products } \\
\hline No & $218(82.9)$ & $236(69.6)$ & $454(75.4)$ \\
\hline Yes & $45(17.1)$ & $103(30.4)$ & $148(24.6)$ \\
\hline
\end{tabular}


Table 4. Respondents knowledge and consumption habits of other agro-resources

$\begin{array}{lll}\text { Pregnant women/nursing mothers } & \text { Elderly people } & \text { Total } \\ \mathrm{n}(\%) & \mathrm{n}(\%) & \mathrm{n}(\%)\end{array}$

\begin{tabular}{lccc}
\hline Knowledge of baobab fruit & $10(2.3)$ & $14(3.3)$ & $24(2.8)$ \\
No & $416(97.7)$ & $404(96.7)$ & $820(97,2)$ \\
Yes & & & \\
Consumption of baobab fruit & $52(12.2)$ & $121(28.9)$ & $173(20.5)$ \\
No & $374(87.8)$ & $297(71.1)$ & $671(79.5)$ \\
Yes & & & \\
Knowledge of Aloe vera & $24(5.6)$ & $68(16.3)$ & $92(10.9)$ \\
No & $401(94.4)$ & $349(83.7)$ & $750(89.1)$ \\
Yes & & & \\
Consumption of Aloe vera & $219(51.4)$ & $286(68.9)$ & $505(60.0)$ \\
No & $207(48.6)$ & $129(31.1)$ & $336(40.0)$ \\
Yes & & $15(3.6)$ & $51(6.1)$ \\
Consumption of pineapple, orange, and spinach & $36(8.5)$ & & \\
No & $389(91.5)$ & & \\
Yes & & & \\
\hline
\end{tabular}

Reasons for consuming soybean products and other agro-resources

Reasons for consuming soybean products were reported by only $39.3 \%$ of study participants. Soybean products were mainly consumed for their nutritional values (44.6\%) and 39.9\% of study participants reported consuming them because it was trendy. Reasons for this consumption by study population are listed in Figure 1 below.

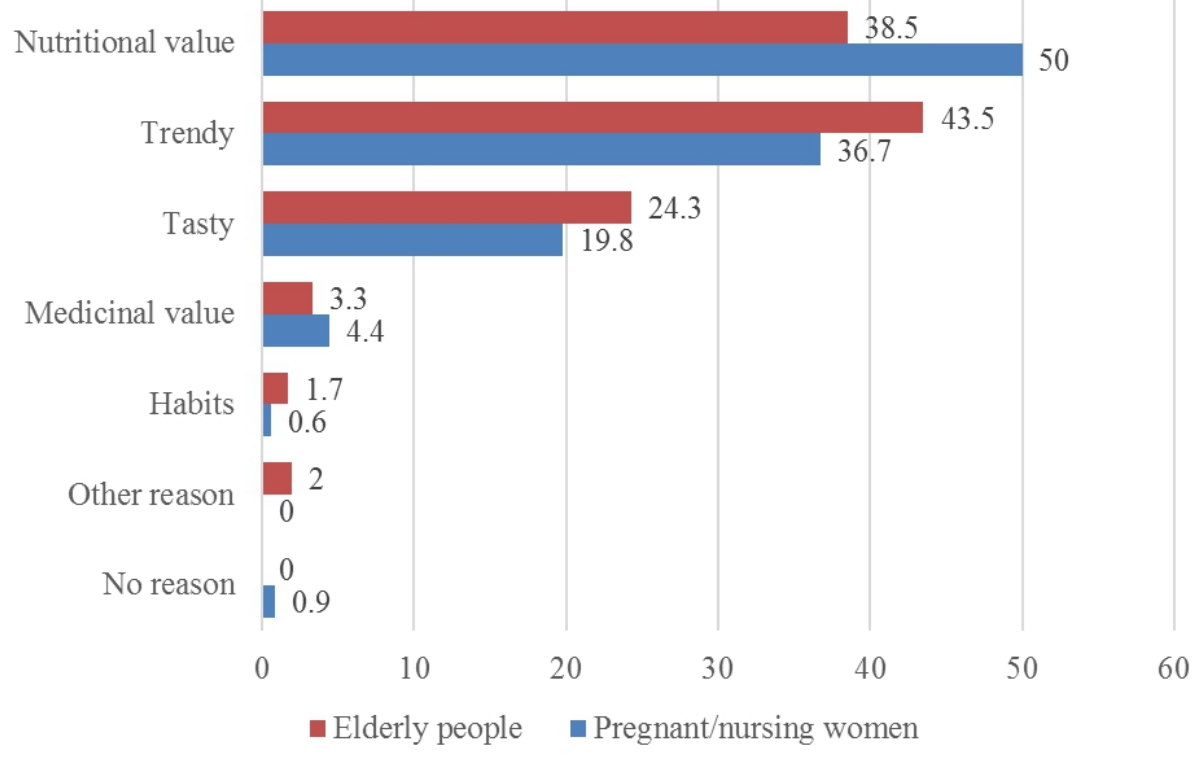

Figure 1. Reasons for consuming soybean products. 


\section{Discussion}

According to our purpose which is to assess knowledge and consumption patterns of soybean, Moringa oleifera in two vulnerable groups of populations in Lome, the majority of respondents (96\%) knew soybean and Moringa oleifera, regarding the knowledge and $76.8 \%$ said that they had already consumed soy-containing products. This proportion was $79.5 \%$ among pregnant women and nursing mothers, and $74.1 \%$ among elderly people. Regarding Moringa oleifera, 71.2\% of the respondents have consumed its finished products. Pregnant and nursing women accounted for $61.7 \%$ and the elderly accounted for $80.9 \%$ of them. However, only $12.5 \%$ have consumed soymilk and $3.2 \%$ have consumed moringa drink.

This survey was the first study conducted in two populations such as the elderly and pregnant /nursing women in Togo with a significant sample size (more than 800 subjects). It provides reliable data on the food knowledge and practices of these populations with respect to soybeans and other agricultural resources.

A similar study was conducted in Nigeria in the population of Orumba South Local Government Area of Anambra State, with the enrolment of 180 respondents. The elderly accounted for $8.3 \%$ of this population. In this study, the majority (more than $70 \%$ ) of respondents had knowledge of soy products. Expectant and nursing mothers have been educated on the processing and use of soybean. Soy products are widely accepted and consumed by over $50 \%$ of adults, $60 \%$ of housewives and more than $90 \%$ of growing children. About $70 \%$ of breastfeeding mothers were educated on the rich source of soy protein and accepted soy products such as soymilk, soymilk powder, etc., to be processed into infant formula (Ugwu \& Nwoke, 2011). Another study conducted in Ghana (75\% of the population was between 30 and 40 years old) reported that $18 \%$ of the 150 respondents liked soy drink while $19 \%$ liked fruit juice (Quarcoo, 2008). Based on these different studies, we can say that soy products are well-known and consumed by population in the West African region.

Another study conducted on 496 subjects in Iran revealed higher rates of soy product consumption (soy protein, soymilk) among the elderly (33.06\%). Soy protein was consumed at $673 \pm 81 \mathrm{~g} / \mathrm{month}$ and soy yogurt at $420 \pm 148 \mathrm{~g} / \mathrm{month}$ in the study (Sadeghian et $a l ., 2015$ ). Information on soy consumption is well known in Asia (Chen et al., 1999), where Chinese women aged 41-50 years had lower consumption compared with both younger and older women (Sadeghian et al., 2015). In Canada, although soymilk and tofu consumption rates were generally low among respondents, elderly individuals showed the highest soymilk consumption rate, and tofu consumption rate was highest among individuals between 25 and 54 years of age (Nesbitt et al., 2008). 
In our study, $39.3 \%$ of respondents reported consuming soy products for specific reasons such as habits, nutritional value and taste. Tofu and soy flour are more popular in target populations. Complementary data from our discussions with the participants indicated that the processing ability and low cost are the reasons associated with this preference in Lome. In Lomé, pregnant and nursing women learned from the information sessions they received from clinics, hospitals and maternity hospitals, as well as from various educational media. The least consumed products are soymilk and moringa drink because of their difficult storage and processing.

The benefits of soy are varied. According to Martin, soybean is rich in proteins that are close to certain animal proteins such as milk or egg (reference protein). It contains more protein than beef and more calcium than in eggs (Jacobs, 1951; Morrison, 1936). It also has an advantageous lipid profile with few saturated fatty acids and contains no cholesterol or lactose (Martin, 2012)..

Soymilk consumption can be an alternative to those who are intolerant to cow's milk lactose. It will also be a good way of popularizing the other forms of our local agro-resources such as soya and moringa drink in local areas rather than using raw products.

Regarding Aloe vera, many of the respondents consume it because it is used as a remedy against digestive diseases, caries, hair and skin diseases. Aloe vera soap, toothpaste and ointment are the most used products. Baobab fruit is also accepted and consumed because of its nutritional value and ability to treat some diseases according to respondents.

Some respondents have a positive attitude because of their taste or the trend, or consider it as a cure for some diseases such as cancer and rickets; among other respondents, it is a lifestyle inherited from their ancestors.

There might have been selection bias in our study because respondents were selected using convenience sampling technique. Respondents who are more sensitive to the topic under study-that is agroresources- were more likely to accept to participate in the study. There was a possible bias due to food intake recall.

Ultimately, the main conclusions of our study were obtained only by using questionnaires. The results are based solely on respondents' statements, since no objective parameter measurement (for example, biological indicators) was foreseen in the protocol. As a matter of fact, this is an inherent limitation of the investigation method, since we have no other way that would help us confirm their declaration. Consequently, having no option but to rely on the good faith of the respondents, we provided them with as much information as possible to have them cooperate objectively for the study. They were first of all, assured that their statements will be completely anonymous. Then, we clearly explained to every respondent, the objectives of the study. They were informed that the data collected will be useful for a better understanding of 
their attitudes towards the consumption of local agro-resources, and in the medium and long run, could contribute for their protection as consumers. To make sure that our explanations were well understood, we took special care in selection of our interviewers; we made sure that they had a keen sense of communication and patience so as to listen and reassure respondents. We had a well-trained team and also insisted on their linguistic abilities (knowledge of vernacular languages) so as to re-explain the message without disguising it.

With all these methodological precautions, we performed this survey with confidence that the answers gathered would be sincere.

\section{Conclusion}

Assessment of knowledge and consumption patterns of nutritious agroresources needs to be expanded to the entire study populations all over our country, so as to provide a more complete database. Further studies including children, young active adults in several cities other than capital also need to be conducted. As suggested by other studies, it would be interesting to evaluate the relationship between soy and moringa compound products consumption and the risk factors of non-communicable diseases in individuals (for example, measuring BMI as a standard factor for obesity and cardiovascular disease risk assessment). Moreover, we could also test through another survey, the most common health claims about soy and moringa-based products in less vulnerable populations in our country. Improvement of relevant factors would thus be measured in case of those foodstuffs consumption.

Ultimately, at a time when food insecurity affects a large majority of the world population and where public issues are very strong, more education is needed. It would be based on rigorous studies to promote healthier diets and a better understanding of the related allegations relevance. This would help develop a more critical consumer mind about misinformation that may be conveyed about local processed foods.

\section{Acknowledgements}

The authors are grateful to Eyram Adjogah, David Mawuvi, Bright Ahiaba and Essèboe Sewu for their valuable assistance with data collection. Competing interests: The authors declare that they have no competing interests.

\section{References:}

1. Adeniyi, A. B., Laurence, C. E., Volmink, J. A., \& Davids, M. R. (2017). Prevalence of chronic kidney disease and association with cardiovascular risk factors among teachers in Cape Town, South Africa. Clinical Kidney Journal, 10(3), 363-369. https://doi.org/10.1093/ckj/sfw138 
2. Cappuccio, F. P., \& Miller, M. A. (2016). Cardiovascular disease and hypertension in sub-Saharan Africa: burden, risk and interventions. Internal and Emergency Medicine, 11(3), 299-305. https://doi.org/10.1007/s11739-016-1423-9

3. Chiwanga, F. S., Njelekela, M. A., Diamond, M. B., Bajunirwe, F., Guwatudde, D., Nankya-Mutyoba, J., ... Dalal, S. (2016). Urban and rural prevalence of diabetes and pre-diabetes and risk factors associated with diabetes in Tanzania and Uganda. Global Health Action, 9(1), 31440. https://doi.org/10.3402/gha.v9.31440

4. Dalal, S., Beunza, J. J., Volmink, J., Adebamowo, C., Bajunirwe, F., Njelekela, M., ... Holmes, M. D. (2011). Non-communicable diseases in sub-Saharan Africa: what we know now. International Journal of Epidemiology, 40(4), 885-901. https://doi.org/10.1093/ije/dyr050

5. Darre, T., Amana, B., Pegbessou, E., Bissa, H., Amegbor, K., Boko, E., ... Napo-Koura, G. (2015). Descriptive Epidemiology of Thyroid Cancers in Togo. Asian Pacific Journal of Cancer Prevention: APJCP, 16(15), 6715-6717.

6. Guwatudde, D., Nankya-Mutyoba, J., Kalyesubula, R., Laurence, C., Adebamowo, C., Ajayi, I., ... Dalal, S. (2015). The burden of hypertension in sub-Saharan Africa: a four-country cross sectional study. BMC Public Health, 15, 1211. https://doi.org/10.1186/s12889015-2546-z

7. Hever, J., \& Cronise, R. J. (2017). Plant-based nutrition for healthcare professionals: implementing diet as a primary modality in the prevention and treatment of chronic disease. Journal of geriatric cardiology: JGC, 14(5), 355.

8. Hussein, A. A., Helder, M. N., de Visscher, J. G., Leemans, C. R., Braakhuis, B. J., de Vet, H. C., \& Forouzanfar, T. (2017). Global incidence of oral and oropharynx cancer in patients younger than 45 years versus older patients: A systematic review. European Journal of Cancer, 82, 115-127.

9. Jacobs, M. B. (1951). The chemistry and technology of food and food products. (Vol. 72). LWW.

10. Martin, M. (2012). La graine de soja: transformation et valeur ajoutée. Ouagadougou: WISHH. Consulté à l'adresse http://www.wishh.org/wp-content/intpresentations/burkinafaso2012/Mike\%20Martin\%20InstaPro.pdf

11. Morrison, F. B. (1936). Feeds and Feeding. Soil Science, 42(5), 395.

12. Nesbitt, A., Majowicz, S., Finley, R., Pollari, F., Pintar, K., Marshall, B., ... Knowles, L. (2008). Food consumption patterns in the Waterloo 
Region, Ontario, Canada: a cross-sectional telephone survey. BMC Public Health, 8, 370. https://doi.org/10.1186/1471-2458-8-370

13. Pio, M., Goeh-Akue, E., Afassinou, Y., Baragou, S., Atta, B., Missihoun, E., \& Ehlan, K. (2014). [Young heart failure: epidemiological, clinical and etiological aspects in the teaching hospital Sylvanus Olympio of Lomé]. Annales de cardiologie et d'angeiologie, 63(4), 240-244. https://doi.org/10.1016/j.ancard.2014.04.008

14. Quarcoo, P. (2008). Development of moringa oleifera leaf beverage. Kwame Nkrumah University of Science and Technology. Consulté à l'adresse http://oatd.org/oatd/record?record=oai\%5C $\% 3 \mathrm{Ahttp} \% 5 \mathrm{C} \% 3 \mathrm{~A} \% 5 \mathrm{C} \%$ 2F\%5C\%2Fir.knust.edu.gh\%5C\%3A123456789\%5C\%2F644

15. Sadeghian, M., Hajishafiee, M., Izadi, V., Vahidianfar, F., \& Azadbakht, L. (2015). Soy product consumption and association with health characteristics and dietary quality indices in Isfahan, Iran. ARYA Atherosclerosis, 11(Suppl 1), 94-101.

16. Ugwu, D. S., \& Nwoke, U. M. (2011). Assessment of Soybean Products Acceptability and Consumption in Orumba South Local Government Area of Anambra State Nigeria. International Research Journal of Agricultural Science and Soil Science, 1(8), 314-325. 